\title{
LA TEOLOGÍA DEL PUEBLO Y LA TEORÍA POPULISTA: UNA COMPARACIÓN ENTRE SCANNONE Y LACLAU
}

\author{
Alejandra M. Salinas* \\ Universidad Nacional de Tres de Febrero \\ \asalinas@untref.edu.ar
}

Recibido: 7 de julio de 2020

Aceptado: 26 de agosto de 2020

DOI: 10.46553/colec.31.2.2020.p41-71

Resumen: La teología de Juan Carlos Scannone y la teoría de Ernesto Laclau conciben al pueblo como la unidad principal de análisis y el protagonista de la vida política. En su visión el pueblo es el conjunto de los oprimidos por ciertos sectores sociales y por el capitalismo global. La tarea evangélica en Scannone y el proyecto político en Laclau invocan la necesidad de liberar al pueblo de sus opresores, para lo cual Scannone defiende un modelo de pueblo auto-organizado y Laclau propone construir una hegemonía populista bajo el mando de un líder. Este trabajo ofrece una lectura comparativa de sus escritos desde un ángulo teórico-político: la primera parte resume las raíces históricas e intelectuales, y la segunda parte aborda la metodología empleada, los sujetos políticos, la visión de la justicia y las instituciones, y sus críticas al marxismo y al liberalismo.

Palabras clave: teología del pueblo; teorías del populismo; Juan Carlos Scannone; Ernesto Laclau; filosofía política contemporánea

\begin{abstract}
The theology of Juan Carlos Scannone and the theory of Ernesto Laclau conceive the people as the main unit of analysis and the protagonist of political life. In their vision, the people are oppressed by certain social sectors and by global capitalism. The evangelical task in Scannone and the political project in Laclau invoke the need to liberate the people
\end{abstract}

\footnotetext{
* Licenciada en Ciencias Políticas y Doctora en Sociología (Pontificia Universidad Católica Argentina).
} 
from their oppressors. At the institutional level, Scannone defends a model of a selforganized people, and Laclau proposes to build a populist hegemony under the command of a leader. This work offers a comparative reading of their writings from a theoretical-political angle: the first part summarizes the historical and intellectual roots, and the second part addresses the methodology used, the political subjects, the vision of justice and institutions, and their critiques of Marxism and Liberalism.

Keywords: Theology of the People; Theories of Populism; Juan Carlos Scannone; Ernesto Laclau; Contemporary Political Philosophy

\section{Introducción}

¿Qué tienen en común y de diferente la teología del pueblo y la teoría del populismo? Este artículo busca responder la pregunta con referencia a la obra de Juan Carlos Scannone (1931-2019) y Ernesto Laclau (1935-2014), partícipes activos en las reflexiones sobre la historia, la cultura y la política en la Argentina y en América Latina, el primero en el rol de sacerdote y profesor en un seminario jesuita y el segundo como militante socialista, profesor e investigador. Sus contribuciones giran en torno al pueblo como unidad principal de análisis, sujeto preferente de la acción social y protagonista de la vida política, ideas cristalizadas en los libros La teología del pueblo: raíces teológicas del papa Francisco (Scannone 2017) y La razón populista (Laclau 2009). Los estudios sobre las dos teorías han sido amplios en los respectivos campos disciplinares, aunque todavía está pendiente un análisis conjunto enfocado desde una mirada teórico-política. ${ }^{1}$ Por lo tanto, se ofrece aquí una lectura comparativa de la teología del pueblo de Scannone y la teoría populista de Laclau desde ese ángulo, estructurada

${ }^{1}$ Para el aporte teológico de Scannone ver Galli (1994, 71-77); para la recepción de Laclau en círculos académicos europeos y en América Latina ver, respectivamente, Critchley y Marchart (2008) y Coraggio y Laville (2014). Una comparación de los dos autores desde una perspectiva teológica continuadora del legado intelectual de Scannone es la de Cuda (2019). Una introducción breve y completa, si bien crítica, de la teología del pueblo se encuentra en Bosca (2013). 
en dos partes: la primera aborda las raíces intelectuales de los dos autores y su incorporación en los escritos tempranos, y la segunda parte presenta los argumentos esgrimidos principalmente en los libros mencionados, señalando sus similitudes y divergencias.

Las raíces históricas e intelectuales de sus obras se remontan a la década del sesenta. En el caso de Scannone, su reflexión está asociada a los documentos episcopales de Medellín (1968) y de San Miguel (1969), que resaltaron el lugar central del pueblo en la Iglesia latinoamericana, entendiendo al pueblo como el conjunto de los pobres, oprimidos y excluidos. Por esa misma época, Laclau elaboraba sus ideas de cara a los desafíos que enfrentaba el socialismo en el marco del contexto político argentino. Su posición cuestionaba la conveniencia de un partido desentendido de consideraciones nacionales y populares, por lo cual propuso crear un movimiento en base a un sujeto popular amplio que propulsara las reformas sociopolíticas deseadas. El pueblo se convirtió así en protagonista de dos visiones que propugnaban una nueva Iglesia y la instauración de un nuevo orden político, en el marco de una ola de movilizaciones y de la propagación del llamado revolucionario extendido por toda América Latina.

En diálogo y en parcial oposición con esos fenómenos sociales, lo largo del tiempo Scannone y Laclau se posicionan frente al marxismo y al liberalismo como interlocutores, y postulan que la unidad principal de análisis no es la lucha de clases ni los individuos sino el sujeto pueblo, en su doble rol de víctima y protagonista de la vida política. Sin embargo, existen diferencias entre los dos autores que giran en torno a las cosmovisiones filosóficas y religiosas subyacentes a la noción del pueblo, a su identidad y a las implicancias institucionales que se siguen de esas diferencias. En las páginas que siguen se analizan estas ideas, mencionando también algunas falencias en los campos metodológico y normativo. 


\section{EI concepto de pueblo en los textos de los años sesenta y setenta}

\section{II.1 El aporte de los documentos eclesiásticos}

En términos del alcance de su influencia, el Concilio Vaticano II (19621965) fue un "acontecimiento decisivo de la historia eclesial moderna y el núcleo de una teología católica renovada" (Galli 2012). Las perspectivas volcadas en el documento conciliar Gaudium et Spes (1965), y con mayor énfasis en la carta encíclica Populorum Progressio de Pablo VI (1967), fueron recibidas y reelaboradas en América Latina en las sucesivas reuniones episcopales. El encuentro regional realizado en Colombia en 1968 fue el primer espacio conjunto de reflexión sobre el rol de la Iglesia a partir de los cambios introducidos por el concilio. ${ }^{2}$ El documento suscripto por los obispos en Medellín ofrece un diagnóstico y una evaluación de la situación social en la región: encuentra que la pobreza extendida es injusta e insolidaria, y es causada por la dependencia de los países más poderosos; anticipa la reversión de esa situación "a costa de cualquier sacrificio" si bien condena la violencia, y establece como prioridad pastoral una "preferencia efectiva" por los sectores más pobres, necesitados y segregados (CEAL $1968,11,19,21,68)$. Un año después, los obispos argentinos adaptan esas reflexiones en el llamado Documento de San Miguel, donde convocan a formar una "Iglesia pobre" en sentido espiritual y material, e invitan a eliminar las "estructuras injustas y opresoras" y a emprender una "acción liberadora o salvífica desde la perspectiva del pueblo y de sus intereses" (CEA 1969, III, IV, VI).

Un recorrido por los documentos episcopales mencionados revela un creciente énfasis y variadas acepciones conferidas a la palabra "pueblo": en sentido religioso, como comunidad creyente; en sentido sociológico, como forma de vida de una población; en sentido económico, asociado al grado de desarrollo, y en sentido político, en tanto sinónimo de sujeto colectivo con capacidades y con derechos (ya sea referido a toda la ciudadanía, o a un grupo en particular). Así, de las 57 entradas para pueblo en Gaudium et Spes, diez son de tipo religioso y remiten al pueblo de Dios, 36 son de tipo

\footnotetext{
2 El contexto sociopolítico de la reunión de Medellín es resumido en Migliore (2018,
} 145-150). Sobre el documento de los obispos ver Galli (1994, 23-29). 
sociológico y hacen referencia a los pueblos del mundo, otras diez aluden a los pueblos en vías de desarrollo y desarrollados, y una sola vez se mencionan los pueblos hambrientos y los opulentos. En Populorum Progressio, se registra un número similar de entradas, de las cuales dos aluden al Pueblo de Dios, la mitad remite al pueblo como población, y el resto de las menciones son para los pueblos hambrientos, opulentos o ricos, desarrollados/en vía de desarrollo, independientes/ fuertes y débiles. Se pone de manifiesto el creciente interés de la jerarquía eclesiástica en los fenómenos socioeconómicos, tanto en relación a los principios y valores generales como en lo relativo a propuestas concretas como, por ejemplo, la defensa de la planificación económica estatal como vía al desarrollo (Pablo VI 1967, § 26, 33).

Los textos episcopales latinoamericanos muestran un uso similar del vocablo pueblo. En el Documento de Medellín de un total de 104 entradas para el vocablo pueblo, 48 revisten un sentido sociológico (pueblos/ comunidades de América Latina; la paz entre los pueblos/ hermanos de otros continentes; la fe de los pueblos; pueblos periféricos/marginados); 44 son entradas religiosas relativas al Pueblo de Dios (Israel; la Iglesia; América Latina; cristianos/creyentes), y 12 son entradas políticas referidas a los intereses, la fuerza, o la dignidad del pueblo; la participación y promoción social; el pueblo concientizado, organizado o auto-determinado (CEAL 1968). En el ámbito pastoral, el pueblo es entendido como "los sectores más pobres y necesitados y a los segregados por cualquier causa”, por lo cual se convoca a "una distribución de los esfuerzos y del personal apostólico que [les] dé preferencia efectiva" (CEAL 1968.).

Igual tendencia se observa en el Documento de San Miguel, donde se cuentan 53 menciones de pueblo: 24 en sentido religioso, 18 en sentido político y 11 de tipo sociológico (poblaciones del mundo, de América Latina, y de la Argentina). Al diagnóstico de la pobreza extendida se suman las prescripciones que guían el camino de salida: dado que Dios no hizo al hombre para vivir en la miseria, hay que denunciar la "carencia injusta de los bienes"; promover la igualdad propia del cristianismo; adoptar la pobreza material como gesto solidario con los que sufren, "trabajar por la liberación total del hombre e iluminar el proceso de cambio de las estructuras injustas y opresoras". Además, se incluye una acepción cultural que resalta "el aporte fecundo de los auténticos valores y sanas tradiciones 
originadas desde el comienzo de nuestra nacionalidad que reflejan el genuino espíritu de nuestros pueblos" (CEA 1969, IV).

La línea interpretativa anclada en lo nacional-popular, lo históricocultural, y lo asistencial-pastoral se profundizaría a partir de ese momento. En el documento emitido luego de la reunión episcopal regional en Puebla en 1979, la palabra pueblo en sentido sociopolítico tiene completa preeminencia, ya que de las 368 menciones poco más de trescientas están asociadas a la pobreza, la periferia, la opresión o la liberación, y 34 a la violencia y la revolución (Celam 1979). El texto de Puebla sigue la misma prescripción pastoral que el de Medellín, con su "amor preferencial pero no exclusivo por los pobres" y "su aliento a una liberación integral de los hombres y de los pueblos" (Celam 1979), observando que "la apertura pastoral de las obras y la opción preferencial por los pobres es la tendencia más notable de la vida religiosa latinoamericana" (Celam 1979).

En suma, en los años sesenta y setenta el pueblo ocupa gradualmente un lugar central, entendiéndolo en un sentido sociopolítico y pastoral como aquellos grupos sumidos en la pobreza, en la opresión o en la marginalidad, situaciones que debían atenderse de forma prioritaria. A partir de entonces gran parte de la Iglesia latinoamericana fue pensada principalmente en torno al sujeto pueblo, su identidad e historia serían leídas en clave de conflicto o dependencia, y su futuro renovado se asociaría a un cambio radical. Este último adjetivo alude aquí al carácter exhaustivo del cambio propuesto (alcanzando las estructuras y prácticas sociales, las instituciones de gobierno, etc.), antes que al radicalismo entendido como manifestación de violencia, ya que ésta fue rechazada por todos los documentos episcopales como vía para alcanzar la transformación social. En vista de la rápida difusión de la violencia, los discursos papales en Medellín y en Puebla advirtieron: "No podemos escoger ni el marxismo ateo, ni el de la rebelión sistemática, ni tanto menos el del esparcimiento de sangre y el de la anarquía" (Paulo VI 1968); “esta concepción de Cristo como político, revolucionario, como el subversivo de Nazaret, no se compagina con la catequesis de la Iglesia. (...) quienes tienen a su cargo los ministerios de la comunidad, y han de contar con la colaboración de todo el Pueblo de Dios" (Juan Pablo II 1979, énfasis agregado).

Tales fueron los fundamentos señalados para continuar con la renovación eclesiástica y social postconciliar en América Latina. En el caso argentino, 
parte del clero profundizó una perspectiva centrada en el pueblo-pobre como sujeto preferente de atención pastoral y de la acción social y política. ${ }^{3}$ Esa fue la visión fundacional de los teólogos Lucio Gera y Rafael Tello, entre otros, y nutrió la mirada de Juan Carlos Scannone, quien con el tiempo se convertiría en el pensador "más sistemático y más reconocido" de la línea de pensamiento denominada teología del pueblo (Fresia 2005, 236). ${ }^{4}$ Como analizamos más adelante, en la obra de Scannone el pueblo remite a una categoría pastoral - en tanto destinatario preferencial del mensaje evangélico y sujeto privilegiado para conocer a Dios -, y también constituye una categoría política vinculada a una historia y una cultura local (Scannone $2017,120,167)$. Teología y política se unen así en torno al protagonismo del pueblo y la preeminencia de lo nacional-popular.

\section{II.2 El aporte de la teoría política}

A la par de la renovación eclesiástica promovida por el Concilio Vaticano y del incipiente desarrollo de la teología del pueblo, se había difundido una teoría política que también situaba al sujeto popular en el centro de su atención, con el objetivo de orientar el espíritu de la reforma política hacia una superación de las estructuras dominantes. Esa teoría era la de Antonio Gramsci, y hacia mediados de los años setenta ya era bien conocida y había sido analizada a fondo por la politóloga belga Chantal Mouffe-luego colega y compañera de Laclau-, quien fue una interlocutora importante en la interpretación del filósofo italiano por parte del autor argentino. Lo que Mouffe resalta como aporte fundamental en Gramsci es que no estaba sesgado hacia lo económico, como el marxismo tradicional, sino que daba prioridad a lo político como principal aspecto de la vida social

\footnotetext{
${ }^{3}$ Sin embargo, para otros sacerdotes la única salida para crear al hombre nuevo y liberar al pueblo de la opresión era, invocando el ejemplo del Che Guevara, la revolución armada (Mugica 1973, 15, 22, 27, 33).

${ }^{4}$ Respecto del aporte de Tello ver Forcat (2015). Sobre el pensamiento de Gera ver Galli (2012), Scannone (2017, 41-56) y Azcuy (2018): los dos primeros adscriben a la teología del pueblo, mientras que la última prefiere hablar de "teologías latinoamericanas", donde hay lugar también para las miradas feministas e indigenistas (Azcuy 2018, 119).
} 
(Mouffe 1991, 173, 188). Según esa perspectiva, una "clase fundamental" debía ejercer el "liderazgo intelectual y moral" para llevar adelante la tarea de reformar la cultura, construir una "voluntad colectiva" y alcanzar la hegemonía socialista (Mouffe 1991,189-196). Así, era necesario llevar a cabo una "guerra de posición" como estrategia para desmantelar la ideología burguesa, primero a nivel nacional y luego en el plano internacional (Mouffe 1991, 220-221).

Cabe señalar, sin embargo, que la voluntad popular en Gramsci no debe ser entendida como sinónimo de pueblo-pobre, que él consideraba como el subconjunto de "las clases subalternas e instrumentales". A su juicio, los rasgos de los estratos más pobres, explotados y marginados les impiden "tener concepciones elaboradas, sistemáticas y políticamente organizadas y centralizadas en su desarrollo" (Gramsci 1999, 204). Entendido de esta manera, para Gramsci el pueblo no era ni podía ser un sujeto concientizado, organizado o auto-determinado, ni portador de genuinos valores y tradiciones a rescatar, como postulaban los obispos latinoamericanos. Por el contrario, el carácter disgregado y rústico de la clase subalterna tornaba necesaria la intervención de un líder (el príncipe moderno, el proletariado, el Partido Comunista) en la tarea de conducir al pueblo hacia la construcción de una hegemonía política forjada en nuevos valores nacionales.

Gramci le proveyó a Laclau de una plataforma de términos que alimentarían gradualmente su teoría populista. Los términos "voluntad colectiva y nacional" y "el liderazgo intelectual y moral" serían reemplazados por los de "pueblo" e "instancia hegemónica", aunque se mantiene la lógica causal entre los dos: el sujeto nacional popular emerge en la vida política solo como resultado de la construcción realizada por su líder. En resumen, del bagaje teórico del pensador italiano, Laclau incorpora sus nociones principales fundamentalmente a partir de la lectura provista por Mouffe, rescata la propuesta política e historicista en oposición al perfil económico y universalista del marxismo clásico, y resalta el origen constructivista y hegemónico del proyecto populista.

En términos de la relación entre el pueblo y el líder, Laclau no fue el único receptor y seguidor de las ideas de Gramsci: también Gustavo Gutiérrez se nutrió de éste para guiar el movimiento popular a partir de la filosofía de la praxis. Escribe el sacerdote peruano: "[Si el profeta/teólogo] contribuye a descubrir la significación de los acontecimientos históricos, es 
para hacer que el compromiso liberador de los cristianos en ellos sea más radical y más lúcido. Sólo el ejercicio de la función profética, así entendida, hará del teólogo lo que, retomando una expresión de A. Gramsci, puede llamarse un nuevo tipo de intelectual orgánico" (Gutiérrez 1971, 31). En su visión la Iglesia debía convertirse en forjadora de una hegemonía cultural que combinara comunismo con catolicismo.

Gutiérrez difundió con éxito su reflexión teológico-gramsciana sobre la pobreza en el tercer mundo, e impulsó el surgimiento de la teología de la liberación en la región latinoamericana, justificando "la contraviolencia opuesta a la violencia que produce - y con la que se defiende - el orden existente" (Gutiérrez 1971, 172, 284). Al igual que Mugica, Gutiérrez llama a "la creación de un hombre nuevo" para conformar "una sociedad distinta y solidaria", y sigue al Che Guevara, para quien la "conciencia revolucionaria" se asienta en "el sentido del deber" y no en "el estímulo material" propio del capitalismo (Gutiérrez 1971, 304n127). De este modo, la teoría política de Gramsci se unía a ciertas versiones de la teología de la liberación. Si bien ambas compartían con los documentos episcopales su crítica de las estructuras dominantes, divergían crucialmente en torno a las estrategias para cambiarlas, toda vez que Gramsci y Gutiérrez apelaban a una radicalización ausente en la mirada episcopal, que había rechazado el recurso a la violencia como camino hacia la liberación. ${ }^{5}$

En ese terreno de convulsionados debates y movimientos emergen Scannone y Laclau como formuladores de dos teorías distintivas sobre el pueblo, en algunos textos publicados en los años setenta cuyo análisis abordamos a continuación.

\section{II.3 Pueblo, teología y peronismo en un texto temprano de Scannone}

En uno de sus primeros aportes teóricos a la relación entre teología y política, Scannone sigue a Gutiérrez al definir la teología como una

\footnotetext{
${ }^{5}$ Décadas más tarde, Gera recuerda que en esos tiempos elegir entre la vía armada o la vía pacífica para provocar el cambio social era un "juicio práctico difícil”, que exigía "intuir las consecuencias" y ejercer un "instinto profético" (Gera 2005, 277). No puede menos que resultar curioso asociar tal decisión con una intuición o instinto, cuando los documentos eclesiásticos ya analizados habían rechazado expresamente la vía armada.
} 
"reflexión crítica sobre la praxis de fe de la Iglesia", lo que en sus casos se vale de las categorías de dependencia, opresión e imperialismo. En tal sentido, América Latina es retratada bajo "la opresión del sistema capitalista y del imperialismo", por lo cual el autor llama a dar "respuesta concreta y eficazmente práctica a la opresión y dolor bien reales y determinados que sufre el hombre latinoamericano" (Scannone 1972, 249-263). Sin embargo, el sacerdote argentino marca sus diferencias con el lenguaje de la teología de la liberación, cuestiona sus limitaciones metodológicas, y sugiere otra alternativa posible en el terreno de la praxis:

El uso del instrumental socio-analítico del marxismo [implicaría] necesariamente la exclusión de toda otra salida, como pudiera ser la que fuera fruto de la evolución de movimientos populistas latinoamericanos (...) como por ejemplo, el peronismo. [Éste] ha evolucionado desde un nacional-populismo hasta proponer hoy un socialismo no marxista, de índole nacional y humanista. (Scannone 1972, 251-252)

La cita ilustra un rasgo esencial de la teología del pueblo: el llamado a la liberación no podía ir de la mano de una filosofía determinista, materialista y revolucionaria, sino que debía evolucionar hacia "un proyecto históricopolítico de y para un pueblo [latinoamericano]" (Ibid. 256n15, énfasis original). Ese proyecto había encontrado un eficaz portavoz y ejecutor en el peronismo, y en su doctrina nacional y popular convertida en política oficial del Estado argentino desde 1946. En palabras del sacerdote jesuita López Rosas: "Los socialistas, como los comunistas, son internacionales y no les puede interesar lo que para los argentinos y sobre todo para los peronistas es tan sagrado: la Patria" (López Rosas 1974, 84-85). Según Scannone, se trataba de una "unión histórica" entre el peronismo, el pueblo y el lazo de la caridad teologal; más aún, se trataba de un "nexo necesario" en el sentido de que lo propio y necesario del amor es buscar "servir a la liberación de los hermanos" (Scannone 1972, 256).

El texto de Scannone vincula la identidad popular con su cultura, sus conocimientos, y sus prácticas religiosas. En este sentido el autor encuentra ciertos paralelos en otros dos pensadores argentinos, Carlos Cullen y Rodolfo Kusch, que por esa misma época recurren a lo popular como espacio para pensar la política (Scannone 1972, 231n19, 231n20). Según 
Cullen, la civilización occidental desacreditó la "sabiduría popular" latente en la política, el arte y la religión, por ello apela a la "resistencia popular" (no a la revolución), y a la vida en la pobreza solidaria (Cullen 2015, 161164, 168-170). Por su parte, en Kusch lo popular está marcado por el plano emocional, que "es una racionalidad invertida y simétrica y cumple con la función de proponer una lógica que parta de lo negativo, o mejor de lo que es antagónico respecto a la propuesta intelectual" (Kusch 2015, 409, 414). Todos los autores se posicionaban contra un perfil occidentalista considerado racionalista, materialista y dominante, y proponen incorporar elementos distintivos y propios del saber popular para dejar atrás esa situación.

Además de defender su costado humanista y la cultura nacionalista del peronismo, Scannone apela a un aspecto participativo que cabe destacar: "Es necesario dar condiciones de participación al pueblo, en el cual hay también élites de pensamiento, grupos dedicados a la creatividad en el campo de la economía, de la política, de la tecnología, pero también en el campo sindical y universitario" (Scannone 1972, 272). Se sigue que la participación, al menos de parte del pueblo, es considerada como un canal para generar una disposición pro-activa y creativa conducente a la liberación. La invocación de una cultura política participativa completaba, así, la lectura temprana de Scannone sobre la relación entre la teología popular y la instanciación de un régimen de gobierno y de prácticas políticas que compartieran su credo.

\section{II.4 Pueblo, política y peronismo en un escrito temprano de Laclau}

Al igual que Scannone, a comienzos los años setenta Laclau promueve la instauración del socialismo en la Argentina de la mano de un nacionalismo popular que funcionara como fuerza progresista y revolucionaria (Laclau 1973). Su teoría también asume las tesis de la dependencia y del imperialismo como causa del subdesarrollo regional, y propone elaborar un plan nacional conducido por la clase obrera organizada liderada por Perón. Como se sabe, la instrumentación de ese proyecto fue truncada por el golpe militar de 1955, aunque el peronismo revolucionario se vio fortalecido y comenzó a proyectarse como un "movimiento de vanguardia regional" (Laclau 1973, 126-127). Sin embargo, a partir de 1974 
los sucesos políticos argentinos forzaron al ímpetu revolucionario de ese movimiento a pasar a la clandestinidad y eventualmente desaparecer durante la dictadura militar que gobernó el país entre 1976 y 1983. Con ese contexto como telón de fondo, se publica el primer libro de Laclau, Política e ideología en la teoría marxista, donde a diferencia del texto de 1973 ya no habla de "peronismo revolucionario" sino de ruptura o momento populista, y donde esboza el análisis que ampliará de ahí en más en su teoría apologética del populismo.

En lo que sigue analizamos la segunda sección del último capítulo del libro, titulado "Hacia una teoría del populismo" (Laclau 1978, 186-205). El populismo es presentado como un fenómeno político caracterizado por la articulación de "las interpelaciones popular-democráticas presentadas como un conjunto sintético-antagónico respecto a la ideología dominante" (Laclau 1978, 201). Las nociones de interpelación popular y antagonismo resultan centrales al argumento del autor, y son elaboradas en un diálogo parcialmente cuestionador de las categorías y estrategias marxistas. Frente a la mirada economicista de éstas, Laclau invoca un discurso que agrupe diversas demandas populares (reclamos económicos, políticos, ecológicos, raciales, etc.); contra los reclamos asociados únicamente a la clase proletaria, recurre a las interpelaciones plurales y variables ante el bloque opositor; y frente a la lucha socioeconómica contrapone un antagonismo político cuyas características específicas dependerán de cada contexto histórico. A pesar de estas diferencias, se mantiene el lenguaje revolucionario, reconociendo que el "momento jacobino" puede disolverse cuando es absorbido por los partidos populares, o puede mantenerse y convertirse en una "totalidad sintética" (los regímenes de Mao y de Tito ilustrarían este último caso) (Laclau 1978, 204).

Las nociones de interpelación popular y de antagonismo permiten ser aplicadas a varias ideologías. Así, Laclau distingue entre el populismo llevado adelante por la clase dominante para manipular al pueblo (por ejemplo, el caso de Hitler) y aquel implementado por la clase dominada, que persigue los "verdaderos objetivos del pueblo" (Laclau 1978, 202). Esta distinción opera en un doble nivel de análisis, en términos de las motivaciones del grupo gobernante (manipular o reflejar) y en términos de la naturaleza de las demandas populares (verdaderas en tanto son reales y falsas si no lo son). Se infiere que si un régimen o discurso populista atiende 
demandas verdaderas, será más democrático; en caso contrario estaremos frente a una imposición populista autoritaria. La caracterización del peronismo como populismo es realizada en base a esta distinción: mientras que los elementos militaristas y católicos del peronismo son considerados por el autor como elementos no populares, ${ }^{6}$ su perfil antiliberal reflejaría una ideología popular que confronta con el "discurso oligárquico liberal". De ahí el carácter representativo y popular del peronismo, y la propuesta del "socialismo nacional" (Laclau 1978, 221-224).

\section{El pueblo en los textos tardíos de Scannone y Laclau}

Los argumentos analizados en la sección anterior fueron recogidos y ampliados en los libros La teología del pueblo: raíces teológicas del papa Francisco, publicado en 2017 (en adelante TP), y La razón populista, publicado en 2005 (en adelante $R P$ ). El contexto histórico reciente estaba marcado por un auge de los regímenes populistas en América Latina, y por la elección de Jorge Begoglio, un jesuita argentino discípulo de Scannone, como Papa Francisco. ${ }^{7}$ El clima a comienzos del nuevo milenio resultaba propicio entonces para revisitar las contribuciones de la teología del pueblo y de la teoría populista, y arrojar luz sobre el curso de las ideas y acontecimientos de la época. En esta sección se abordan principalmente los contenidos de los dos libros, en base a una comparación que analiza y evalúa las metodologías empleadas, las nociones de pueblo y antipueblo, las visiones sobre la justicia y las instituciones, y las posiciones frente al pensamiento marxista y liberal.

\footnotetext{
${ }^{6}$ Laclau no aclara en qué sentido en los años cuarenta lo católico no era "popular". Lida (2013) ofrece un análisis de la masiva llegada católica a los medios de comunicación, los jóvenes militantes, los círculos obreros y las escuelas a partir de la década del treinta. ${ }^{7}$ Sobre la influencia de la teología del pueblo en el Papa Francisco ver Cuda (2016) y Scannone (2017, 181-274).
} 


\section{III.1 Los aspectos metodológicos}

Scannone distingue la teología como ciencia (con su pretensión de validez universal) de la visión teológica del pueblo, caracterizada por los rasgos carismáticos, simbólicos y narrativos de la cultura y la sabiduría popular. Sin embargo, señala que la interrelación entre las dos perspectivas no es una de confrontación, sino de complementariedad (TP 155, 170-171). ${ }^{8}$ Las dos perspectivas confluyen en la noción de pueblo como categoría que remite al "sujeto y agente de la historia humana, que está vinculada a la historia de la Salvación" (TP 157). El llamado a la trascendencia es una reflexión teológica universal, pero se instancia en una situación históricocultural concreta y en este sentido se trata de una "universalidad situada", que debe ser juzgada a la luz de la palabra de Dios (Ibid., 154, 163). Para comprender de modo integral los rasgos particulares de esa "universalidad situada", Scannone privilegia las disciplinas humanistas (filosofía, historia, cultura y religión). En este sentido, la cultura desarrollada a lo largo de la historia es el eje central de su análisis; su objeto de reflexión es una cultura popular asentada en sentimientos, valores y prácticas sociales de origen autóctono e hispánico, ampliados luego por la asimilación de elementos migratorios. Uno de los rasgos de la cultura popular así entendida es el sentido de la fraternidad (compasión, solidaridad, etc.). La hipótesis es que la cultura popular ha sido objeto de conflictos y agonismos provocados por los intentos para cambiarla, y por la dependencia de países y grupos que ejercen una dominación sobre el pueblo (TP 79). Así, su lectura teológicahistórica-cultural de esos conflictos se diferencia de las teorías de la dependencia centradas en la explotación social o económica (TP 34, 85-86, 110). ${ }^{9}$

El enfoque interdisciplinario también se aplica al pensamiento de Laclau, quien integra una variedad de metodologías y términos tomados de la filosofía de Gramsci, el enfoque psicoanalítico y el lenguaje del

\footnotetext{
${ }^{8}$ El autor advierte que su enfoque científico está despojado de "resabios iluministas", si bien no indica cuáles son éstos (TP 159).

9 Por ejemplo, en Gera el subdesarrollo es visto como producto de la dependencia económica de los países hegemónicos (Gera 2005, 275-276). En cambio el documento de Medellín habla de "neocolonialismo económico y político" (CEAL 1968, 19, énfasis agregado).
} 
inconsciente de Freud y Lacan, y la propuesta lingüístico-discursiva de Sassure ( $R P$ 147-148). Todos estos aportes confluyen en una teoría que postula la naturaleza contingente y antagónica de la vida social. A diferencia de Scannone, Laclau no utiliza el aporte de las ciencias sociales -más aun, ni siquiera invoca la razón científica- y dicha ausencia es consecuente con la explicación psicológica y discursiva de la vida social. ${ }^{10} \mathrm{Si}$ bien Laclau ignora el aporte de la ciencia, ello no implica afirmar que sea un irracionalista; la suya es una racionalidad de tipo axiológico, en tanto reconoce un valor principal que orienta y otorga cohesión al discurso y la acción populista: ese valor es el afecto, y su rol es central a la construcción discursiva-política. Si el lenguaje maneja conceptos, argumenta el autor, la significación que damos a esos términos tiene una carga afectiva sin la cual no se puede entender la dinámica populista ( $R P$ 142-143).

Una segunda premisa metodológica en Laclau es el antagonismo permanente que el autor introduce como variable principal en la relación entre pueblo y antipueblo. Se trata de una "frontera interna" que los divide, una grieta imposible de cerrar pero cuyas dimensiones varían según el momento histórico. La otra variable es el modo de encuentro entre los dos actores, y funciona como un péndulo que oscila entre el choque revolucionario y la absorción por partidos populistas. En todos los casos, el populismo rompe, transgrede, o subvierte el orden institucional existente, y reconstruye un nuevo orden con mayor o menor radicalidad ( $R P 221,283$ 284).

Una comparación de los abordajes arriba analizados revela varias afinidades y diferencias en las metodologías utilizadas por Scannone y Laclau. Entre las afinidades, en tanto piensan el campo sociopolítico en términos de sujetos colectivos, se inscriben en el colectivismo metodológico (por oposición al individualismo metodológico, cuya unidad de análisis son las preferencias, decisiones y motivaciones de las personas individuales y sus interrelaciones). Además, ambos utilizan un lenguaje con gran carga afectiva para aludir a las motivaciones que impulsan al pueblo, y adoptan la

\footnotetext{
${ }^{10}$ Hay, sin embargo, algún espacio para incorporar rasgos culturales, pero puede decirse que éstos son meros aspectos del discurso político antes que "datos" sobre ciertas costumbres y usos sociales.
} 
premisa del antagonismo o la dominación para enunciar la relación del pueblo con el antipueblo.

Respecto de las diferencias, mientras Scannone encuentra en el aporte científico un complemento de la sapiencia popular, Laclau lo descarta. En relación al dúo constructivismo/ tradicionalismo, mientras el teólogo descubre un ethos popular emergente de las tradiciones propias de cada cultura, el filósofo enfatiza la construcción de lo popular mediante el discurso, de modo que no hay una tradición que respetar, sino una identidad para crear. Por último, la principal diferencia entre los dos autores es señalada por el mismo Scannone, que toma distancia de "la conflictividad permanente, la noción 'gramciana' de hegemonía y la división de la sociedad como estrategia de poder", y descarta de modo explícito el aporte de Laclau para pensar al pueblo $(T P, 90)$.

Llevando el análisis a un plano evaluativo de sus teorías, se ha coincidido en señalar su sesgo reduccionista. Así, la teología del pueblo parece desconocer que "el mensaje de Cristo está dirigido a todos los sectores sociales por igual", y el Pueblo de Dios está encarnado potencialmente en todas las culturas y todas las clases sociales (Irrazábal 2017; Hoevel 2016, 57-58). Entre las críticas a Laclau, según Stuart Hall "la posición totalmente discursiva es un reduccionismo hacia arriba, en lugar de un reduccionismo hacia abajo, como lo fue el economismo" (Grossberg 1986, 56-57). Como vimos, en tanto Scannone vincula lo político a un fenómeno históricocultural, a su vez acotado a lo popular-nacional, y en tanto Laclau reduce lo político a un fenómeno psicológico-discursivo, sus teorías efectivamente se alejan de visiones más pluralistas sobre los fenómenos culturales, y de la integración posible entre los valores y prácticas diversas que habitan lo político.

\section{III.2 Sobre el pueblo y el antipueblo}

En la teología de Scannone, además de ser una categoría pastoral el pueblo es una categoría política con dos acepciones, como nación y como grupo social. En tanto nación, el pueblo designa a una "comunidad orgánica", a un "sujeto colectivo de una historia nacional y su ethos cultural" (TP 120, 124). En tanto grupo social, el pueblo está constituido por los pobres, que son "Juan Pueblo, sin los privilegios del poder, tener o 
saber". A su vez, el rótulo de "Juan Pueblo" se aplica tanto a "los pueblospobres" (las comunidades nacionales en situación de pobreza) como a "los pobres de los pueblos" (los miembros del grupo social más pobre dentro de cada sociedad) (TP 21,11). Por otro lado, las acepciones de nación y grupo están interconectadas, de modo que el pueblo-grupo social funciona como portavoz del pueblo-nación, ya que los pobres "son los que trasparentan mejor y más auténticamente lo común de un pueblo" (TP 21). Dada esta función representativa del pueblo-grupo social, en adelante usaremos el vocablo pueblo en esa acepción.

Los aspectos a resaltar de la identidad del pueblo son la "conciencia de pertenencia" y un "proyecto de bien común" anclado en la justicia, la identidad cultural y la solidaridad (TP 84). El pueblo es capaz de conocerse a sí mismo, ${ }^{11}$ y su cultura refleja una identidad forjada a lo largo del tiempo y eventual objeto de la opresión histórica por parte de grupos portadores de otras culturas dominantes. Quienes no comparten el ethos de la cultura popular pertenecen al "antipueblo", concepto que engloba a todos quienes son considerados como opresores de personas, razas, clases o culturas, y cuya común característica puede ser resumida como la oposición al bien común popular. Así, el antipueblo está compuesto por dos grupos específicos: algunas elites nacionales, y el imperialismo y sus cómplices (TP 84-85, 89, 147).

Dos corolarios se siguen de estos retratos. Primero, lo popular es lo nacional, por oposición a los elementos elitistas y extranjeros que atentan contra esa identidad. Segundo, se vuelve imperativo encarar las acciones necesarias para defender la cultura popular (TP 79). La resistencia, claro está, debe encarar la clásica pregunta, ¿qué hacer? La respuesta de Scanonne es la misma que en 1972: en el ethos popular prevalece el sentido del tiempo y descarta la acción violenta, es cuestión de esperar a integrar las culturas disímiles (TP 148). Su propuesta es continuar con la "opción preferencial" por el pueblo en el ámbito pastoral, en lo económico atender sus necesidades

${ }^{11} \mathrm{Al}$ afirmar que el pueblo puede conocerse a sí mismo, pero no conoce todo, Scannone parece transitar una vía intermedia entre la afirmación de que el pueblo conoce mejor -"la vida del pobre es como un "humus" fecundo que posibilita mejor el acceso a las verdades más profundas" (Fernández 1998, 153-154)-, y la negación de su capacidad de auto-percepción: "la sapiencia popular no es autoconciencia sino memoria" (Cuda 2019, 64, 69-70). 
insatisfechas, en lo simbólico fortalecer la cultura popular, y en lo político adoptar un programa de gobierno donde haya lugar para un rol activo del pueblo y un liderazgo que lo represente sin avasallarlo.

$$
* * *
$$

La lectura de Laclau sobre el pueblo difiere de Scannone en lo relativo al ethos popular, ya que no reconoce una identidad preexistente, esto es, una esencia del pueblo atada a una historia compartida, a sus manifestaciones culturales, a la condición económica o a la religión común. La suya es una mirada que no apela a fundamentos o esencias últimas y definitivas que sostengan una identidad popular concreta, como tampoco una tendencia conducente a formarla a futuro.

Sin embargo, para el autor predicar la inexistencia de fundamentos trascendentes no implica desconocer la necesidad de invocar algún tipo de sustento basal. Si en la visión psicoanalítica de Lacan, un objeto particular encarna la función de representación de una plenitud imposible de alcanzar, y en Gramsci, un grupo particular se convierte en la representación hegemónica de toda la sociedad ( $R P$ 147-148), ${ }^{12}$ en Laclau una fuerza social particular, una "instancia hegemónica" o "líder" recurre al discurso u "operación performativa" para construir y representar al pueblo. La identidad popular funciona como un "significante vacío", esto es, se forma de acuerdo a diversos contenidos ("palabras, imágenes") que remiten a una serie de demandas equivalentes unidas mediante el discurso del líder $(R P$ 122-130). El discurso emitido por el líder cumple una tarea doble: por un lado, construir la identidad del pueblo nucleando distintas demandas, y por el otro definir al antipueblo, cuya identidad y nombre serán indeterminadas

12 Laclau también se inspira en Heidegger, cuyo vocablo "abismo" remite a la aspiración humana por alcanzar el "todo", y a la posibilidad de asignar a éste un contenido que, sin embargo, nunca es pre-establecido ni completo (Laclau 2014, 147 149). Por lo tanto, si bien no adscribe a una trascendencia en sentido religioso, sí reconoce el ansia siempre presente de plenitud o totalidad. Por otro lado, el autor ofrece una analogía entre el discurso de la teología negativa y el de su teoría populista para explicar quién y cómo se ocupará de realizar la tarea de asignar un contenido parcial a esa totalidad (Laclau 2014, 64-65). Ver Salinas (2019). 
(oligarquía, grupos dominantes, etc.). El líder crea así una "frontera interna”, metáfora que remite a la confrontación o antagonismo entre el pueblo y el antipueblo (RP 114,117).

De acuerdo con este razonamiento, la identidad popular varía con cada experiencia histórica, marcada siempre por la contingencia librada a la suerte de los eventos, personalidades, estrategias y discursos de turno. Se sigue que no es posible postular la identidad popular de acuerdo a paradigmas universales. Admitir la validez de estos presupuestos no excluye, para Laclau, reconocer que el pueblo siempre es el conjunto de demandas sociales insatisfechas que se consideran excluidas u oprimidas. Por lo tanto, un conjunto indeterminado de elementos sociales heterogéneos confluirán en las distintas variantes de una hegemonía populista ( $R P 125)$.

La distinción de Scannone entre pueblo-nación y pueblo-pobre es traducida por Laclau a términos políticos clásicos, donde populus son "todos los ciudadanos" y plebs son los "menos privilegiados". En Scannone, el pueblo-pobre es portavoz o representante de una cultura atribuible también al pueblo-nación, pero esta representatividad es imposible en el modelo de Laclau, donde no existe una entidad cultural homogénea que pueda ser representada. Pueblo es cualquier instancia particular, surgida de un universo de elementos heterogéneos, que ocupa y define el espacio popular: así, esa plebs "reclama ser el único populus legítimo" (RP 107-108).

En lo referente al líder popular, éste no presenta capacidades cognitivas superiores ni cualidades extraordinarias de mando; simplemente emerge de entre las demandas insatisfechas para ocupar el lugar de representante, y es reconocido como tal por el pueblo, por lo cual es un liderazgo democrático ( $R P$ 83-84). Más aún, pueblo y líder están unidos en una identificación afectiva, "absolutamente crucial", que enlaza los sentimientos del grupo con su líder (RP 282). ${ }^{13}$

Un resumen comparativo del abordaje sobre el pueblo y el antipueblo indica que Scannone presupone la unidad cultural del pueblo forjada en la

${ }^{13}$ Cabe señalar, empero, que la relación entre líder y pueblo no está exenta de tensiones: si bien el líder representa las diferentes demandas heterogéneas existentes y forma la cadena de equivalencias, su construcción política siempre debe mantener relación con esas demandas, que preservan cierto grado de autonomía frente al líder. En la medida en que el líder las desoiga, o que las demandas cobren mayor autonomía frente al líder, crecerá la tensión entre ellos ( $R P$ 204-205). 
historia, y su énfasis está puesto en el pueblo como un sujeto activo, con tareas propias vinculadas a la historia de la Salvación. En contraste, la lectura de Laclau difiere de Scannone en lo relativo al ethos del pueblo y a la naturaleza la dinámica política: la emergencia y la identidad del pueblo dependen de la voluntad y del discurso del líder (no hay posibilidad de autoorganización), y la dinámica política no contempla como exigencia del modelo una actitud participativa por parte del pueblo que complemente o avale la gestión representativa del liderazgo.

En última instancia, tanto Scannone como Laclau defienden pero al mismo tiempo restringen al pueblo como actor político. El esquema del teólogo le reconoce mayor autonomía y capacidades creativas, pero lo ata a una cultura nacional definida de una vez y para siempre en el pasado histórico. En este sentido encontramos en Scannone un tradicionalismo o comunitarismo que clausura la posibilidad de auto-renovación popular en base a elementos culturales distintos de esa tradición. En el caso de Laclau, no se reconoce al pueblo como un actor político autónomo, ya que lo somete a la voluntad performativa del líder al momento de crearse la identidad popular, y lo sujeta a la función representativa del líder sin invocar la participación popular directa. Por último, si bien Laclau describe y defiende la causa de las demandas populares, no ofrece herramientas para evaluar el éxito de esa causa, pues solo atiende al surgimiento, la continuidad y las tensiones que enfrenta la operación hegemónica en manos del líder.

\section{III.3 Justicia, instituciones y liderazgo}

En su libro Scannone hace referencia al valor o ideal de la justicia en términos de "justicia estructural" y "justicia social" (TP 84, 127), y las relaciona con el bien común del pueblo, si bien no enuncia ningún principio de justicia en particular. Un principio de justicia es el que establece cuándo y de acuerdo a qué criterios es legítimo reconocer a cada uno lo suyo, esto es, cuándo afirmar que ciertos sujetos, acciones, instituciones o situaciones son justos. Al respecto, por ejemplo, un principio de justicia sería efectuar una mejor "distribución de los bienes y servicios destinados originariamente a todos" (Juan Pablo II 1987, § 28). Otra modalidad es formular distintos principios de justicia según los valores que se defiendan. Así, es justo satisfacer las necesidades vitales básicas de las personas; es justo respetar 
la igualdad de los ciudadanos y la reciprocidad de los socios, y es justo reconocer el mérito respectivo de quienes reciben el fruto de su trabajo (Schmidtz 2006, 11, 18-19, 164, énfasis agregado).

La ausencia de formulación de algún principio de justicia no impide que Scannone evalúe la evolución histórica en términos de justicia. Según su perspectiva, el pueblo ha sido y continúa siendo víctima de la opresión y la injusticia, cuyos artífices son los "imperialismos" y sus "cómplices", resultando en la conformación de "élites que gozan de injustos privilegios". La denuncia es acompañada por el llamado a luchar por una nueva sociedad más justa (TP 85, 89, 147). Ahora bien, cuáles son los indicadores históricos de las injusticias cometidas; a lo largo de cuánto tiempo, cuán graves son éstas, y quiénes deben asumir la responsabilidad por ellas son aspectos que quedan sin tratamiento. ${ }^{14}$ La enunciación y el reclamo prevalecen sobre la justificación del argumento acerca de la naturaleza y la extensión de las injusticias cometidas, así como de la evaluación de alternativas para implementar las reparaciones correspondientes.

La ausencia de algún contenido positivo de la noción de justicia en la obra de Scannone es, en sus propios términos, el único aspecto que lo une al pensamiento de Laclau en torno a la noción de "significante vacío" de justicia, y "según contra qué tipo de injusticia (económica, política, racial, de género, discriminación religiosa...) se luche y qué justicia se reinvindique" (TP 90). Esta posición acerca a Scannone al énfasis discursivo de Laclau. Cuando éste habla de justicia toma el concepto como un "significante vacío", es decir, sin contenidos a priori ni definitivos; al igual que con el concepto de pueblo, un significante vacío sólo cobra sentido en tanto asociado a una determinada "operación performativa" ( $R P$ 126-127). Desde su ángulo, los ideales como justicia, libertad, igualdad, solidaridad, etc. son palabras que remiten a una variedad múltiple (aunque no infinita) de posibles contenidos surgidos del discurso político. Afirma al respecto:

\footnotetext{
$14 \mathrm{Si}$ los responsables de la injusticia cometida contra las poblaciones americanas originarias fueron los Estados europeos colonizadores, mediante las guerras de conquista y las apropiaciones forzadas de recursos materiales y de personas, un criterio de reparación básico sería la devolución de tierras propiedad del Estado a los descendientes de las víctimas de la confiscación inicial, en conjunto y por única vez, sin afectar a los terceros inocentes de tales perpetraciones.
} 
[La justicia] no tiene un contenido propio y necesita tomarlo de algunas de las propuestas normativas que se presentan a sí mismas como encarnaciones de la justicia. Supongamos que un contenido tal como 'socialización de los medios de producción' comienza a desempeñar ese papel (...) no solo significa lo que la expresión directamente designa, sino también el fin de todas las injusticias existentes en la sociedad: la injusta distribución del ingreso, la desigualdad en el acceso a los medios de consumo, las oportunidades desiguales de acceso al empleo, todo tipo de discriminación social, etc. (...) Este es el momento del investimiento ético en lo normativo. (Ibid., 164, énfasis agregado).

El párrafo ilustra la fuerza asignada a la retórica populista, y la ausencia de justificación de su propuesta y del diagnóstico sobre las injusticias de la situación precedente. ¿Por qué sería justo socializar los medios de producción, en función de qué valores o fines? ¿De qué manera esa propuesta pondría fin a todas las injusticias? ¿En qué situaciones y en qué medidas la desigualdad actual resulta injusta? Otras miradas han intentado dar una respuesta justificada a estas preguntas básicas de la filosofía política. ${ }^{15}$ Pero la teoría populista no puede dar una respuesta debido a las propias restricciones del modelo, que escapa a cualquier visión sustantiva de la justicia y se focaliza en el rol del discurso performativo.

En lo que toca a la justicia, entonces, los modelos teóricos de Scannone y Laclau se acercan: son los discursos y las prácticas sociales los que asignarán un determinado contenido a los reclamos de justicia para el pueblo. En sus obras, la justicia es una palabra vacía, pero las injusticias existentes tienen contenidos y responsables específicos que deben ser combatidos con miras a una reforma. Es en esta última instancia cuando aparecen entonces las cuestiones institucionales: ¿mediante cuáles mecanismos institucionales, y a cargo de quién/es, sería posible instanciar las reformas conducentes a asegurar justicia para el pueblo?

\footnotetext{
${ }^{15}$ Por ejemplo, Rawls formula dos principios básicos de justicia: el derecho individual a una igual libertad y derechos básicos, y la aceptación de las desigualdades cuando beneficien a los menos favorecidos, y cuando exista la igualdad de oportunidades (Rawls 1999, 266-267). Ver Salinas (2012).
} 
Las respuestas a estas preguntas están conectadas, al igual que en los textos de los años setenta, con la historia y la propuesta política del peronismo, que según Scannone expresó el ideal de justicia social, sumado a los de soberanía política e independencia económica (TP 127). El discurso peronista así entendido sería compatible con una gestión de lo público con participación popular, y con un comunitarismo en todas las dimensiones de la vida social (TP 35, 87). ${ }^{16} \mathrm{Su}$ análisis rescata el legado institucional de España con sus prácticas populares y democráticas, pero al mismo tiempo reconoce que también habría forjado un estilo político personalista y caudillista, que sin embargo no habría impedido asimilar los aportes liberales de la ley y la constitución para controlarlo (TP 149). De este modo, el balance entre personalismo e institucionalismo en Scannone arroja un saldo positivo tanto en términos teóricos como en lo relativo a la experiencia histórica.

En el caso de Laclau, si bien su teoría del populismo es una apología de la lógica peronista, aplicada a la experiencia histórica de los años setenta su análisis es menos positivo. Desde el ángulo teórico, el discurso peronista de justicia social debía recurrir a la articulación de diversas demandas para lograr reconstruir la hegemonía populista finalizada con el golpe militar de 1955. El problema surgió cuando las tensiones al interior de esa articulación socavaron fatalmente el proyecto de reconstrucción. En palabras de Laclau: "Entre la burocracia sindical de derecha, por un lado, y la juventud peronista y las "formaciones especiales", por el otro, no había nada en común: se consideraban el uno al otro como enemigos mortales. (...) Perón intentó durante un tiempo hegemonizar de un modo coherente la totalidad de su movimiento pero fracasó" ( $R P$ 273-274). En contraste con Scannone, el balance entre el liderazgo personalista y la estabilidad institucional arrojó un saldo negativo para esta última. Como consecuencia, no solo sufrió el proyecto particular de justicia social que defendía el peronismo, sino la democracia en su conjunto.

\footnotetext{
${ }^{16}$ No hay suficiente espacio aquí para desarrollar más la idea de comunitarismo y vincularla a la propuesta de Scannone. Para un análisis de algunas teorías comunitaristas contemporáneas ver Saiz (2015).
} 


\section{III.4 Las posiciones frente al marxismo y al liberalismo}

Tanto la teología del pueblo como la teoría populista fueron elaboradas en diálogo con teorías marxistas. Entre los referentes de la teología de la liberación, Scannone cita a E. Dussel, G. Gutiérrez y los hermanos Boff. Por su parte, Laclau se inspira principalmente en Gramsci para criticar las posiciones marxistas más clásicas. Sus obras presentan puntos de acuerdo y de desacuerdo con el corpus teórico marxista, que cambian a lo largo del tiempo. En el caso de Scannone, se mantiene la crítica a la visión unívoca y determinista del marxismo expresada cuarenta años antes, pero se observa un tono más conciliador al hablar de la "mutua fecundación" entre la teología de la liberación y la del pueblo; se trataría de un mismo paradigma con distintos acentos (TP 25-27). ${ }^{17}$ Como en 1972, ese paradigma mantiene como su principal unidad de análisis a los pobres y oprimidos, y focaliza su crítica en las estructuras y procesos de dominación y opresión.

La teoría de Laclau, en cambio, sufre cambios considerables en ese mismo período. Si antes hablaba de clases, modo de producción y revolución, ahora piensa en el pueblo, en el discurso político y en la hegemonía populista. Al igual que Scannone, toma distancia del método marxista de análisis social y de sus estrategias de acción: rechaza la lucha de clases, la idea de una sociedad comunista reconciliada y el presupuesto de que lo económico determina todas las esferas sociales, para sostener que no existe "un sistema transparente y racional de relaciones sociales" y que lo político no "es expresión de movimientos económicos subyacentes" ( $R P$ $105,184)$. Ni determinismo, ni dialéctica, ni materialismo: las identidades sociales no se derivan de las relaciones de producción sino son introducidas por la política. Dicho esto, Laclau es un "postmarxista" y no un "antimarxista", porque si bien critica la idea de que exista una esencia humana asociada al conjunto de las relaciones sociales, ${ }^{18}$ comparte con el marxismo clásico su objetivo final, la instauración del socialismo.

${ }^{17}$ Para una lectura similar ver Cuda $(2019,64)$.

${ }^{18}$ En la VI Tesis sobre Feuerbach Marx afirma que "la esencia humana no es algo abstracto inherente a cada individuo. Es, en su realidad, el conjunto de las relaciones sociales". La lectura posmoderna de Laclau cuestiona y abandona este esencialismo como premisa filosófica subyacente a su teoría política. 
A pesar de sus críticas, Scannone y Laclau resaltan ciertas afinidades y simpatías con el marxismo, en contraste con su completo rechazo de los presupuestos antropológicos, éticos e institucionales del liberalismo, vinculados a su individualismo metodológico y axiológico y al sistema económico capitalista. En realidad, se trata más bien de una reconstrucción del pensamiento liberal, ya que ninguno de los dos cita autores liberales (como sí hacen con los marxistas). En el caso de Scannone, su cuestionamiento está enfocado primero en las cuestiones éticas y cognitivas del individualismo liberal: si por un lado lo asocia con valores burgueses consumistas, por el otro lado lo tilda de elitismo iluminista $(T P 35,80)$. En segundo lugar su crítica al capitalismo se basa no tanto en su funcionamiento o dinámica interna sino en las consecuencias que dice provocar, como por ejemplo, la exclusión social. Este retrato es acompañado por la invitación para "superar la supremacía del capital sobre el trabajo" (TP 89). Sin embargo, el autor no explicita una propuesta para adoptar un sistema económico alternativo, en contraste con su defensa anterior de un socialismo humanista (Scannone 1972, 252).

El antiliberalismo/anticapitalismo de Scannone se inscribe en una tradición católica de larga data. Tomemos como ilustración moderna la opinión volcada en Populorum Progressio: "Este liberalismo sin freno, que conduce a la dictadura, justamente fue denunciado por Pío XI como generador de "el imperialismo internacional del dinero" (Pablo VI 1967, $\S 26$ ). Existen, sin embargo, otras miradas a la relación entre sistema económico y doctrina social de la Iglesia que concilian la premisa de la creación de riqueza y los mercados libres con los valores católicos (Chafuen 2013; Zanotti 2005). Lamentablemente, la teología del pueblo pasa por alto el análisis de la compatibilidad entre catolicismo y capitalismo, incluso cuando ya en 1991 el Papa había afirmado que el modelo para el progreso económico y civil es el capitalismo, entendido como "un sistema económico que reconoce el papel fundamental y positivo de la empresa, del mercado, de la propiedad privada y de la consiguiente responsabilidad para con los medios de producción, de la libre creatividad humana en el sector de la economía” (Juan Pablo II 1991, § 42).

Como señalamos en las secciones anteriores, también Laclau rechaza el individualismo metodológico del liberalismo y su aspiración a promover valores universales para las nociones de justicia e igualdad, y encuentra en 
el sistema capitalista global el epítome del antipueblo. Alineado con el marxismo en cuanto la invocación de una crisis capitalista, para el autor ésta no surge de las contradicciones internas del sistema sino que es introducida de modo político. La premisa descriptiva es que el funcionamiento del capitalismo provoca la exclusión de grupos sociales, crisis ecológicas, desempleo masivo, y desequilibrio general, creando así las condiciones para que surja el populismo en tanto movimiento articulador de los "sujetos anticapitalistas globales" ( $R P$ 191, 285-287). Laclau no ofrece evidencia empírica ni cita literatura especializada sobre las variables que enumera como indicadores del impacto capitalista en la sociedad. Tal ausencia es consistente con su postura metodológica discursiva, según la cual un programa político populista se construye con palabras y con herramientas emocionales, y no en base al estudio científico de la realidad social.

\section{Conclusiones}

Tanto Scannone como Laclau anclan la noción de pueblo en demandas o grupos insatisfechos y en marcos histórico-culturales particulares a cada sociedad. En su visión, el pueblo es el conjunto de los pobres y marginados, oprimidos por ciertas elites y por el capitalismo mundial. Frente a esa opresión, la tarea evangélica de liberación en Scannone y el proyecto político en Laclau comparten como premisa principal la necesidad de defender al pueblo del antipueblo, fortaleciendo la cultura y las instituciones nacionales y populares, y construyendo un régimen hegemónico, respectivamente. En tal sentido podemos hablar de un mismo paradigma populista en la teología y en la teoría política aquí analizadas, anclado en el colectivismo metodológico, ético, político y económico.

Sus miradas, sin embargo, presentan diferencias importantes. Para Scannone, el pueblo está llamado a ser protagonista de la historia humana y salvífica, y posee un ethos emergente de una historia nacional que refleja una cultura popular común. Esa cultura tiene una visión trascendente y está comprometida con la opción preferencial por los pobres y oprimidos, en sentido pastoral y también político. En contraste, para Laclau el pueblo es un sujeto construido a partir de la intervención de un líder y mediante un discurso que no tiene ningún fundamento fijo. Así, la identidad popular tiene 
un carácter contingente, y el imaginario populista se presenta variable y pragmático. Si en Scannone el fenómeno cultural y religioso popular recorre un curso histórico hacia la trascendencia, en Laclau cultura, religión y demás fenómenos sociales están al servicio de las variaciones de cada proyecto populista.

Las dos visiones también se diferencian respecto a sus implicancias institucionales. Para remediar la opresión causada por el antipueblo, Scannone celebra el proyecto de un pueblo participativo y auto-organizado, mientras que en Laclau no hay tal posibilidad de auto-organización toda vez que el pueblo depende de la voluntad e iniciativa del líder expresadas en su discurso. Su modelo no requiere tampoco de la participación popular, ya que por definición un régimen populista es una instancia de pura representación, más compatible con los fenómenos de movilización y aclamación que con la posibilidad de una intervención independiente en la esfera pública. Dicho esto, el punto histórico del encuentro entre la teología del pueblo y la teoría populista fue el peronismo, en tanto síntesis y expresión de los valores nacionales, populares y hegemónicos.

Por último, cabe recordar dos de las principales críticas formuladas al paradigma populista, tal como es entendido en este trabajo. Por el lado metodológico, y para decirlo en pocas palabras, el sesgo reduccionista consiste en pensar que todo lo político es cultural (Scannone) y que todo lo político es discursivo (Laclau). Por el lado normativo, los cuestionamientos señalados son que el rechazo del capitalismo no está fundamentado con datos empíricos ni con citas de la literatura especializada, y que una propuesta popular en el sistema democrático argentino debiera admitir más alternativas que las presentadas por el peronismo.

A más de cincuenta años de sus primeras formulaciones, la teología del pueblo y la teoría populista han sido y siguen siendo influyentes a escala global, convertidas en corrientes de pensamiento, en prácticas sociales y en guías para la acción política. Este trabajo se propuso comparar sus fundamentos con el fin de comprender mejor las realidades políticas actuales, y así contribuir a analizar cuáles caminos convendría seguir - y cuáles resultaría prudente y justo evitar- a la hora de adoptar, implementar y evaluar las propuestas de reforma en las sociedades contemporáneas. 


\section{Referencias}

Azcuy, Virginia. 2018. "Lucio Gera, un teólogo de Medellín”. Revista de Teología 126: 103-131.

Bosca, Roberto. 2013. "En el nombre del pueblo. La categoría de pueblo en la política y en la teología". Anales de la Academia nacional de ciencias morales y políticas, Buenos Aires. Disponible en: https://www.ancmyp.org.ar/user/files/03-Bosca13.pdf

Chafuen Alejandro. 2013. Raices cristianas de la economía de libre mercado. Santiago de Chile: Fundación para el Progreso.

Concilio Vaticano II. 1965. Constitución Pastoral Gaudium et Spes: sobre la Iglesia en el mundo actual.

Conferencia Episcopal Argentina (CEA). 1969. Conclusiones de Medellín [Documento de San Miguel].

Conferencia General del Episcopado Latinoamericano y del Caribe (CELAM). 1979. Documento de Puebla. III Conferencia General del Episcopado Latinoamericano.

Consejo Episcopal Latinoamericano (CEAL). 1968. Conclusiones de la Segunda Conferencia General del Episcopado Latinoamericano, Medellín.

Coraggio, José Luis y Jean-Louis Laville (comp.). 2014. Reinventar la izquierda en el siglo XXI. Hacia un diálogo Norte-Sur. Los Polvorines: Universidad Nacional de General Sarmiento.

Critchley, Simon y Oliver Marchart (comp.). 2008. Laclau: aproximaciones críticas a su obra. Buenos Aires, Fondo de Cultura Económica.

Cuda, Emilce. 2016. Para leer a Francisco. Teología, ética y política, prólogo de Juan Carlos Scannone, Buenos Aires: Manantial.

2019. "Latinoamérica en el siglo XXI: posmarxismo, populismo y teología del pueblo". Cuadernos de Filosofia Latinoamericana 40 (121): 57-75.

Cullen, Carlos. 2015. Fenomenosofia de la crisis moral. Sabiduría de la experiencia de los pueblos. Buenos Aires: Las Cuarenta [1978].

Fernández, Víctor M. 1998. "El sensus populi: la legitimidad de una teología desde el Pueblo”. Teología 72: 133-164.

Forcat, Fabricio. 2015. "En las nacientes de la Pastoral Popular. Rafael Tello entre los Peritos de la COEPAL". Stromata 71: 145-159. 
Fresia, Iván Ariel. 2014. "Teología del pueblo, de la cultura y de la pastoral popular. A propósito de los primeros escritos teológicos de Scannone". Stromata 70: 227-236.

Galli, Carlos. 1994. "El pueblo de Dios en los pueblos del mundo. Catolicidad, encarnación, e intercambio en la eclesiología actual”. En $L a$ encarnación del Pueblo de Dios en la Iglesia y en la eclesología latinoamericanas. Tesis Doctoral, Cap. V, Facultad de Teología de la UCA, Buenos Aires.

2012. "Lucio Gera: un precursor de la teología latinoamericana contemporánea", CELAM. Disponible en:

http://www.celam.org/observatoriosociopastoral/detalle_noticias.php?i $\mathrm{d}=\mathrm{NTQ}=$

Gera, Lucio. 2005. "La teología de los procesos históricos". Revista de Teología XLII (87): 259-279.

Gramsci, Antonio. 1999. Cuadernos de la Cárcel, Vol. 6, ed. V. Gerratana, México: Era.

Grossberg, L. (ed.). 1986. "On Postmodernism and Articulation: An Interview with Stuart Hall”. Journal of Communication Inquiry 10 (2): 45-60.

Gutiérrez, Gustavo. 1971. Teología de la Liberación. Perspectivas. Lima: Editorial Universitaria.

Hoevel, Carlos. 2016. "La teología política de Francisco: Pueblo, Iglesia y Estado liberal". Rivista di Storiadelle Idee 5 (2): 55-61.

Howarth, David (comp.). 2015. Ernesto Laclau: Post-Marxism, populism and critique. Oxford: Routledge.

Irrazábal, Gustavo. 2017. “Opción por los pobres y pauperismo”, Instituto Acton Argentina, $1^{\circ}$ de julio. Disponible en:

http://www.institutoacton.com.ar/articulos/295art170717-a.pdf

Juan Pablo II (Papa). 1979. "Discurso Inaugural". En Documento de Puebla. III Conferencia General del Episcopado Latinoamericano, págs. 4-22.

- 1987. Carta encíclica Sollicitudo rei socialis.

1991. Carta encíclica Centesimus Annus.

Kusch, Rodolfo. [1973] 2015. "Una lógica de la negación para comprender a América". En Antología del pensamiento crítico argentino contemporáneo, coordinado por Sergio Caggiano y Alejandro Grimson, págs. 409-418. Buenos Aires: CLACSO. 
Laclau, Ernesto. 1973. “Argentina: Peronism and Revolution”. En Latin America Review of Books, compilado por Colin Harding y Christopher Roper, págs. 117-130. Palo Alto: Ramparts Press.

Laclau, Ernesto. 1978. Política e ideología en la teoría marxista: capitalismo, fascismo, populismo. Buenos Aires: Siglo XXI [1977].

—. [2005] 2009. La razón populista, Buenos Aires: Fondo de Cultura Económica.

- 2014. Los fundamentos retóricos de la sociedad. Buenos Aires, Fondo de Cultura Económica.

Lida, Miranda. 2013. "La 'nación católica' y la historia argentina contemporánea". Corpus: Archivos virtuales de la alteridad Americana Vol. 3 (2). Disponible en:

http://journals.openedition.org/corpusarchivos/579.

López Rosas, Ernesto. 1974. "Teología de la liberación: su profundización a partir de la experiencia peronista". Hechos e ideas: Nueva época 4 (mayo-junio): 77-96. Disponible en:

ruinasdigitales.com/revistas/Hechos\%20e\%20Ideas\%2004.pdf

Migliore, Joaquín. 2018. "El 68 en América Latina: el contexto histórico en que nace el evento Medellín”. Revista Colección 29: 137-152.

Mouffe, Chantal. 1991. "Hegemonía e Ideología en Gramsci”, trad. Cristina de la Torre. En Gramsci y la realidad colombiana, págs. 167-227. Bogotá: Ediciones Foro Nacional por Colombia.

Mugica, Carlos (Padre). 1973. Peronismo y cristianismo. Buenos Aires: Editorial Merlín - Colección Sociedad y cambio.

Pablo VI (Papa). 1967. Carta Encíclica Populorum Progressio.

Rawls, John. 1999. A Theory of Justice, revised edition. Cambridge, MA: The Belknap Press of Harvard University Press.

Saiz, Mauro. 2015. "La comunidad para los comunitaristas: A. MacIntyre y C. Taylor”. Analecta política 5 (9): 305-330.

Salinas, Alejandra M. 2012. "La rectificación de la injusticia en Nozick: debates e implicaciones para los reclamos territoriales indígenas". Revista Co-herencia 9 (16): 119-144.

- 2019. "Política y teología: lecturas de Schmitt y Laclau". UNTREF- Proyecto de Investigación Acreditado No 32/383 A.

Scannone, Juan Carlos, S. J. 1972. "Teología y política. El actual desafío planteado al lenguaje teológico latinoamericano de liberación". En $\mathrm{Fe}$ 
cristiana y cambio social en América Latina: encuentro de El Escorial, editado por el Instituto Fe y Seguridad, págs. 247-264. Salamanca: Sígueme.

- 2017. La teología del pueblo: raíces teológicas del papa Francisco. Buenos Aires, Editorial Sal Terrae / Colección Presencia Teológica $\mathrm{N}^{\circ} 251$.

Schmidtz, David. 2006. Elements of Justice. Cambridge: Cambridge University Press.

Zanotti, Gabriel J. 2005. Economía de mercado y Doctrina Social de la Iglesia. Buenos Aires: Instituto Acton. 